\title{
The 40th anniversary of human IVF: time to celebrate and time to reflect
}

\author{
R M L Winston \\ Department of Surgery and Cancer, Imperial College London, London, UK \\ Correspondence should be addressed to R M L Winston; Email: r.winston@imperial.ac.uk
}

Reproduction (2018) 156 E1-E3

The birth of Louise Brown on July 25th 1978 revolutionised clinical practice. This achievement of Steptoe and Edwards, one of the great medical advances of the 20th century, was significant for many reasons. Nothing is more important for most of us than the birth of our children. Moreover, the publicity openly highlighted the burden of childlessness. There have now been over six million births following in vitro fertilisation (IVF) contributing to great happiness of many families; this, indeed, is an anniversary to celebrate. An account of the lengthy struggle of Steptoe and Edwards is (Johnson \& Elder 2015) in an analysis of the records at Oldham General Hospital and at Cambridge. Edwards won the Nobel Prize for Physiology in 2010 and many tributes have been paid to him. We sometimes forget how Jean Purdy, the third member of this pioneering team, was also critically important. A brief video in which Professor Winston celebrates the remarkable achievement of the delivery of the world's first baby born after IVF is also available (Video 1). Professor Winston also points out that forty years on, the success rate for each IVF treatment cycle commenced still remains low with around a $20 \%$ live birth rate. It tends to be even less successful than this in women over 35 years old, paradoxically the age group when many if not most IVF cycles are done. This anniversary should be a reminder that much more research is needed to improve results.

\section{Video 1}

Professor Winston celebrates the remarkable achievement of the delivery of the world's first baby born after IVF but points out that as the success rate for each IVF treatment cycle still remains low much more research is needed to improve results. The video (http:// movie-usa.glencoesoftware.com/video/10.1530/ REP-18-0293/video-1) from the online version of the article is available at https://doi.org/10.1530/REP-180293.

The history of IVF is lengthy. One early attempt at artificial fertilisation is recorded in Pavia (L'Abbé Spallanzani 1789). Convinced that males played some part in making babies, Spallanzani interrupted the foreplay of frogs in his pond, clothed them with tightfitting waxed shorts and replaced the frogs back onto the females. Thereafter, he scraped seminal fluid from the lining of their apparel and inseminating the eggs, produced tadpoles. Mammalian IVF was attempted 100 years later, in Vienna. Samuel Schenk in 1878, inseminating ova from guinea pigs and rabbits, reported cleavage. In 1934, Pincus and Enzmann claimed pregnancies in rabbits, but it is likely that this followed fertilisation by sperm already in the genital tract. In 1944 and 1948, Rock and Menkin published their experience with 800 human eggs, inseminating 138 of them. Their photographs suggest very few developing embryos but these ova were possibly either parthenogenetically cleaved or clumping cells.

Others have made more recent contributions to the beginnings of human IVF. Min Chueh Chang was a Chinese emigré in Edinburgh in 1938. Gaining his PhD in Cambridge, he joined Gregory Pincus at the Worcester Foundation. His discovery of sperm capacitation (Chang 1951) led to achieving IVF; subsequent research helped understand the hormonal environment and embryo transfer. He reported live births of rabbits following IVF (Chang 1959), with further successes in hamsters, mice and rats, ferrets and gerbils. Even leaving aside his work on the contraceptive pill with Pincus, Chang's contribution to reproductive physiology was profound. Embryo transfer was later used to study gene interaction with the environment (McLaren \& Michie 1958). Epigenetics is now of great relevance to those modifying the milieu during human IVF. Her interaction with John Biggers in the 1950s led to induction of ovulation in mice. Subsequently McLaren's presence on the Warnock Committee ensured IVF research continued in Britain when many members of Parliament tried to ban human experiments. In 1990, she became a significant member of the newly formed Human Fertilisation and Embryo Authority (HFEA). Alan Trounson still works with stem cells. After studying farm animals, he became the lead scientist of the successful IVF team at Monash University in Melbourne, Australia. His work on the zona pellucida 
followed McLaren's. His many innovations include human embryo freezing, refinements of superovulation, improvements in embryo culture (Trounson et al. 1976), blastocyst transfer and egg donation. Trounson was always extraordinarily generous in sharing his knowledge.

By 1981 there were only 28 live births from 330 egg collections (Cohen et al. 2005). IVF only gradually became the preferred treatments for Fallopian tube damage or pelvic adhesions, or when both partners were subfertile, or when a cause of infertility was not established. A great advance was in treating male infertility by injection of single spermatozoa directly into the egg, ICSI, described by Gianpiero Palermo in this issue (O'Neill et al. 2018). ICSI is now employed in around $36 \%$ of IVF cycles in Britain. IVF also allowed embryo screening for gene and chromosomal defects in fertile couples at risk of having a baby with a fatal genetic defect; the application of preimplantation diagnosis is recorded in this issue by Alan Handyside (2018) and Griffin and Ogur (2018). Also Fisch and Abir (2018) discuss how ovarian and oocyte preservation has become increasingly valuable in this issue.

Homo sapiens are naturally infertile and most acts of intercourse in menstrual cycles do not result in pregnancy. This low fecundity complicates treatment. IVF success rates in the UK have been recorded for 25 years (HFEA 2017). Currently, only about $21 \%$ of IVF cycles with embryo transfer give a live birth. Success is greater in women under 35 years old but $58 \%$ of women treated with IVF are older and their chance of success is lower. These figures do not tell the entire, depressing story as they do not include all cycles started. Many failures are excluded: for example, patients starting ovarian stimulation but not responding sufficiently to undergo egg collection; those not reaching embryo transfer because fertilisation failed or where the embryos are so fragmented that transfer would be futile. In the US, the latest data from the Centers for Disease Control (CDC 2018) reveal that 231,936 cycles resulted in 60,778 deliveries (26 per cent) but one-third of births were from multiple pregnancies. More pregnancies may have been achieved by transferring more than one embryo simultaneously increasing the risk of perinatal mortality and other physical, mental and financial costs of multiple births. In this respect, the HFEA in the UK has been notably successful in encouraging reduction in the numbers of embryos transferred and promoting embryo freezing. The latest statistics from Australia and New Zealand are similar with 77,721 cycles resulting in $14,040(18.1 \%)$ live births (National Perinatal Epidemiology and Statistics Unit 2015).

Forty years on, IVF remains largely limited to those who can afford it. We have encouraged the public perception that IVF is the treatment for infertility. But reproductive failure has many causes. Optimal treatment may depend on specific intervention for the underlying cause which may be less expensive. But when patients consult their family doctor, or even their gynaecologist, a routine referral to an IVF clinic may mean they may receive standard IVF with little serious attempt at making the diagnosis. The common label 'Unexplained infertility' is not a diagnosis but a failure of diagnosis. It is axiomatic that medicine without a diagnosis may be bad treatment. But this is often ignored in reproductive medicine. Specific therapy for anovulation as Stephen Franks points out in this issue is more successful than IVF and cheaper (White et al. 2018). Selected cases of tubal disease or pelvic adhesions may have a better prognosis with microsurgery or laparoscopic surgery. Most uterine causes of infertility are more likely to respond to treatments, which do not involve IVF.

The HFEA states that an IVF cycle costs between $£ 3000$ and $£ 5000$ (approximately US\$4000-\$6700); this presumably means that this is the cost to the taxpayer when IVF is done under the NHS. But most treatments are done privately and charges are usually higher. The expense of at least two or three cycles merely to give an evens chance of a child means that patients and clinics may avoid investigations. Sometimes unproven treatments add to this burden. These include suppression of the immune system or various doubtful interventions intended to increase the chance of implantation. Unfortunately, the HFEA seems powerless to intervene when patients are offered dubious therapies or even if exorbitant prices are charged.

It must be possible to improve IVF treatment. Above all, we should return to serious research in male gametogenesis and more studies like those of Johan Smitz reported in this issue in female gametogenesis, too (Herta et al. 2018). But in many countries, research has declined, and randomised clinical trials are rare. The financial rewards of reproductive medicine discourage trainees from considering academic careers. And regulatory bodies may discourage researchers. There is some evidence in the UK that the HFEA with various bureaucratic interventions and its requirement for peer review before granting a research licence inhibits academic activity. Out of 87 registered clinics in the UK, some 13 hold licences for embryo research but the HFEA's website suggests a very low application rate or acceptance rate for new research projects. Such regulation was possibly justified 30 years ago when there was apparent public concern about the status of human embryos. But it is hard to understand why a special body is still needed to regulate one area of medicine. In all other, equally challenging specialities, we have excellent research ethics committees.

Restrictive regulation, when it seems irrational, risks professionals evading regulatory intervention and encouraging fertility tourism to less regulated countries. This is not in the interests of good medicine or good for patients. For example, UK treatment for mitochondrial mutations may have been delayed by regulatory procedures, even though Parliament gave approval for 
such work 3 years ago. In America, John Zhang treated a desperate woman from a family suffering several infant deaths from Leigh Syndrome. But the successful outcome of his elegant approach using spindle transfer to prevent mitochondrial disease (Zhang et al. 2017) was made possible only by transferring the management of the patient from New York to unregulated Mexico.

Such research demonstrates what can be achieved with good science. But if the fiftieth anniversary of the work of Steptoe and Edwards is to be celebrated as it should, it will be because research, sensibly scrutinised and responsibly undertaken, will have led to greater clinical improvements, hopefully with less cost.

\section{Declaration of interest}

The author declares that there is no conflict of interest that could be perceived as prejudicing the impartiality of this editorial.

\section{Funding}

This research did not receive any specific grant from any funding agency in the public, commercial or not-for-profit sector.

\section{References}

Centers for Disease Control and Prevention 2018. (available at: https:// nccd.cdc.gov/drh_art/rdPage.aspx?rdReport=DRH_ART.ClinicInfo\&rdRe questForward=True\&Clinicld=9999\&ShowNational $=1$ )

Chang MC 1951 Fertilising capacity of spermatozoa deposited in the Fallopian tubes. Nature 168607-608. (https://doi.org/10.1038/168607a0)

Chang MC 1959 Fertilisation of rabbi ova in vitro. Nature 184 466-467. (https://doi.org/10.1038/184466a0)

Cohen J, Trounson A, Dawson K, Jones H, Hazekamp J, Gosta-Nygren K \& Hamberger L 2005 The early days of IVF outside the UK. Human Reproduction Update 11 439-460. (https://doi.org/10.1093/humupd/ dmi016)

Fisch B \& Abir R 2018 Female fertility preservation: past, present and future. Reproduction 156 F11-F27. (https://doi.org/10.1530/REP-17-483)
Griffin DK \& Ogur C 2018 Chromosomal analysis in IVF: just how useful is it? Reproduction 156 F29-F50. (https://doi.org/10.1530/REP-17-683)

Handyside AH 2018 Designer babies' almost thirty years on. Reproduction 156 F75-F79. (https://doi.org/10.1530/REP-18-0157)

Herta AC, Lolicato F \& Smitz JEJ 2018 In vitro follicle culture in the context of IVF. Reproduction 156 F59-F73. (https://doi.org/10.1530/REP-180173)

Human Fertilisation and Embryo Authority 2017 Fertility treatment 2014-2016 trends and figures. (available at: https://www.hfea.gov.uk/ media/2563/hfea-fertility-trends-and-figures-2017-v2.pdf)

Johnson MH \& Elder K 2015 The Oldham Notebooks; an analysis of the development of IVF 1969-1978 I-VI. Reproductive Biomedicine and Society Online 1 1-70. (https://doi.org/10.1016/j.rbms.2015.04.006)

L'Abbé Spallanzani 1789 Dissertations Relative to the Natural History of Animals and Vegetables. Volume II, Murray, London. (available at: https://catalog.hathitrust.org/Record/000912530)

McLaren A \& Michie D 1958 Factors affecting vertebral variation in mice. Experimental proof of the uterine basis of a maternal effect. Journal of Embryology and Experimental Morphology 6 645-659.

National Perinatal Epidemiology and Statistics Unit 2015 Australian \& New Zealand Assisted Reproduction Database (ANZARD). (available at: https://npesu.unsw.edu.au/sites/default/files/npesu/data_collection/ Assisted\%20Reproductive\%20Technology\%20in\%20Australia\%20 and $\% 20$ New\%20Zealand\%202015.pdf)

O'Neill CL, Chow S, Rosenwaks Z \& Palermo GD 2018 Development of ICSI. Reproduction 156 F51-F58. (https://doi.org/10.1530/REP-18-8011)

Trounson AO, Willadsen SM \& Rowson LE 1976 The influence of invitro culture and cooling on the survival and development of cow embryos. Journal of Reproduction and Fertility 47 367-370. (https://doi. org/10.1530/jrf.0.0470367)

White DM, Hardy K, Lovelock S \& Franks S 2018 Low-dose gonadotropin induction of ovulation in anovulatory women: still needed in the age of IVF. Reproduction 156 F1-F10. (https://doi.org/10.1530/REP-17-697)

Zhang J, Liu H, Luo S, Lu Z, Chávez-Badiola A, Liu Z, Yang M, Merhi Z, Silber SJ, Munné S et al. 2017 Live birth derived from oocyte spindle transfer to prevent mitochondrial disease. Reproductive BioMedicine Online 34 361-368. (https://doi.org/10.1016/j.rbmo.2017.01.013)

Received 7 June 2018

First decision 12 June 2018

Revised manuscript received 12 June 2018

Accepted 18 June 2018 